\title{
Chinese SMEs and Information Technology Adoption
}

\author{
Michelle W. L. Fong \\ Victoria University, Melbourne, Australia
}

Michelle.Fong@vu.edu.au

\begin{abstract}
In China, small and medium enterprises (SMEs) tend to be slow in adopting and exploiting information technology (IT) as a means of enhancing their sustainability. It is vital for such firms to adopt IT in order to keep up with an IT-based global business environment. Otherwise, they may find themselves at a severe competitive disadvantage. This paper provides an insight into the low adoption of IT in the Chinese SMEs. In addition, it examines how financing constraints and the lack of skilled IT talent within these enterprises can explain the low uptake of IT and the low priority given to IT investment.
\end{abstract}

Keywords: SMEs, IT adoption, IT investment, financing, IT talents.

\section{Introduction}

SMEs constitute an important economic sector in China because they are significant sources of wealth and employment. Although the individual contribution of a SME to the national economy may appear relatively insignificant when compared to a large corporation, the aggregate contribution of all SMEs can be sizeable. For example, the average main business revenue of a Chinese SME was seven times less than that of a large Chinese enterprise in 2007 but together all SMEs accounted for more than 50\% of the country's GDP (Yearbook of China SMEs, 2008). The importance of this economic sector is also highlighted by its growing presence within the newlyemerged market economy. There were about 8 million Chinese SMEs in the late 1990s, and they have now grown to more than 40 million entities, representing over $99 \%$ of the total number of enterprises. In addition, these enterprises provided more than $75 \%$ of employment in the economy in 2008.

However, SMEs tend to have a higher mortality rate than larger corporations, and researches have variously associated their business failure with insufficient productivity, competitiveness, business and management skills, financing and access to proper advice and information, and with lost export and business development opportunities (Freland \& Morris, 1976; Jennings \& Beaver, 1997; Koh \& Maguire, 2004; Koh \& Simpson, 2005; Patterson, Kozmetsky, \& Ridgway, 1983;

Material published as part of this publication, either on-line or in print, is copyrighted by the Informing Science Institute. Permission to make digital or paper copy of part or all of these works for personal or classroom use is granted without fee provided that the copies are not made or distributed for profit or commercial advantage AND that copies 1) bear this notice in full and 2) give the full citation on the first page. It is permissible to abstract these works so long as credit is given. To copy in all other cases or to republish or to post on a server or to redistribute to lists requires specific permission and payment of a fee. Contact Publisher@InformingScience.org to request redistribution permission.
Watson, 2003; Wichmann, 1983). At the same time, these SMEs tend to be slow in adopting and exploiting IT as a means of enhancing their sustainability.

In spite of the information technology productivity paradox not being entirely resolved by way of empirical verification (The IT productivity paradox refers to the failure of the advancement in computer technology and its expected 
benefits to be fully reflected in the productivity statistics at the firm and national aggregate levels.), there has been increasing evidence of positive contributions from information technology (Brynjolfsson \& Hitt, 1995, 1996; Hitt \& Brynjolfsson, 1996; Lee \& Barua, 1999; Lichtenberg, 1995; Silvius, 2006). In addition, evidence of increasing adoption of IT by firms (ITU, 2009) implies a widespread belief in the business disadvantages of not doing so. Therefore, it appears vital for these SMEs to adopt IT in order to keep up with an IT-based business and market environment.

Businesses have adopted IT to optimize business processes such as planning, control, collaboration and communication, addressing information needs and internal operations and expectations, making timely and informed decisions, and implementing business strategies. Other reasons for adopting IT in business processes include improving financial performance and operational efficiency (Barua, Konana, Whinston, \& Yin, 2004; Johnson \& Scholes, 1993), attaining flexibility and agility in responding to increased market pressure and changes (Gosain, Malhotra \& El Sawy, 2004; Snow, Miles, \& Coleman, 1992;), achieving competitive advantage (King, Grover, \& Hufnagel, 1989; Monteiro \& Macdonald, 1996; Porter \& Miller, 1985; Rackoff, Wiseman, \& Ulrich, 1985), participating in new forms of alliances enabled by electronic linkages such as virtual organisations, supplier-customer value-chains, company networks, and collaborative networks (Bala \& Venkatesh, 2007; Camarinha-Matos \& Afsarmanesh, 2005; Davidow \& Malone, 1992; Gulati, 1998; Lee, Pak, \& Lee, 2003; Mowshowitz, 1997; Walton \& Miller, 1995; Wei \& Wang, 2010) and participating in new market structures, such as the virtual market or electronic marketplace, to expand business opportunities (Koh \& Simpson, 2005; Stockdale \& Standing, 2004).

Information technology (IT) has indeed changed the dynamics of running businesses. The proper application of information technology and the use of information systems may offer opportunities for SMEs to overcome some of the aforementioned barriers and to improve their survivability in a competitive environment. Prater and Ghosh (2006) found in their study that smaller firms should definitely harness IT capabilities to compete in the global market. Researchers have also raised the possibility of developing strategic alliances or networks through IT to overcome the disadvantage of size, allowing SMEs to compete with larger corporations while remaining small and flexible (Malecki \& Tootle, 1996; Suarez-Villa, 1998).

The use of IT is well documented for large organisations (Prater \& Ghosh, 2006) and there is now an expanding body of research on SMEs' IT adoption. However, the IT adoption of SMEs in developing countries such as China remains limited. This paper adopts a combination of quantitative and qualitative surveys, and review of literature published in China. It draws upon information from about 800 Chinese SMEs in a survey conducted in 2008 and also surveys conducted by Chinese scholars to provide a scenario on the level of IT adoption in Chinese SMEs. In addition, it examines financing constraints and the lack of skilled IT talent within these enterprises as possible reasons for the low uptake of IT and the low priority given to IT investment.

\section{IT Adoption in Chinese SMEs}

In China, $40 \%$ of SMEs are still in their early phase of development and are largely lacking in the experience and resources (financial and management) to compete in overseas markets (Chen, 2009). The export competitiveness of China's SMEs is weaker than both larger corporations in the domestic scene and their overseas SME counterparts. This research found that a significant percentage of SMEs in different Chinese regions, with the exception of Guangdong, were not involved in export trading. Guangdong has traditionally been an export-oriented province because of its coastal locality, and about $60 \%$ of its SMEs are involved in export trading. In other areas such as Hubei, Jiangsu, Liaoning, Yunan, Zhejiang, and Beijing, an average of $70 \%$ of SMEs are not involved in export trading and have indicated that they wish to expand their businesses through other means that require fewer financial resources and lower set-up costs. For example, 
the Internet can offer SMEs the opportunity (via e-commerce) to find new customers and expand beyond their local markets. This technological medium has been regarded as a cheaper means of accessing the global marketplace (Poon \& Swatman, 1997). However, the survey indicates that these Chinese SMEs are involved in a limited range of business activities in e-commerce. Their level of trust for new business features such as online payment is low, because of their unfamiliarity with security issues. These enterprises tend to utilise the Internet only for basic purposes. A large number of their online activities are directed towards product-oriented information search retrieval and announcements (advertising and brand building). The IT usage profile indicates a low adoption of electronic interconnection for strategic use. For example, although about $80 \%$ of the SMEs have electronic interconnection capability, about half of them utilised it largely for email communications. In addition, $23 \%$ of these enterprises established a webpage for business information purposes (such as product advertising, announcements and information dissemination) while $18 \%$ established a web portal for strategic business purposes. eCommerce participation was significantly low, with only $13 \%$ of these enterprises adopting IT applications for this purpose. It is vital for SMEs to adapt to the Internet and exploit it for strategic use, otherwise they will face stiff competition from online competitors with first mover advantages (Jeffcoate, Chappell, \& Feindt, 2002). This position was reinforced in a study by Poon and Swatman (1997) of 23 Australian small businesses, most of whom believed that not having an Internet presence would soon become a competitive disadvantage.

In China, SMEs located in the Central and Western regions were considerably less competitive than their counterparts in the Eastern region. Economic progress in the Central and Western regions has been lagging behind that of the Eastern region. SMEs located in these poorer regions are generally exposed to fewer growth opportunities than those in the East because the latter have comparatively greater access to research and development skill pools, investment, and technology. Therefore, it is important that the less competitive Central and Western SMEs not be excluded from the mainstream of economic activities. IT may offer an opportunity for these less advantaged enterprises to integrate into domestic and global economic systems, and for the country to achieve a balanced growth across all regions.

This study also found that an average of $58 \%$ of Chinese SMEs acknowledged the importance of a market information system for sustaining or improving their competitiveness in the market place. This importance has also been reinforced by a separate survey of Chinese SMEs (Yi, 2010), which asked them to nominate the areas which they deemed in need of IT support (as per Figure 1). 


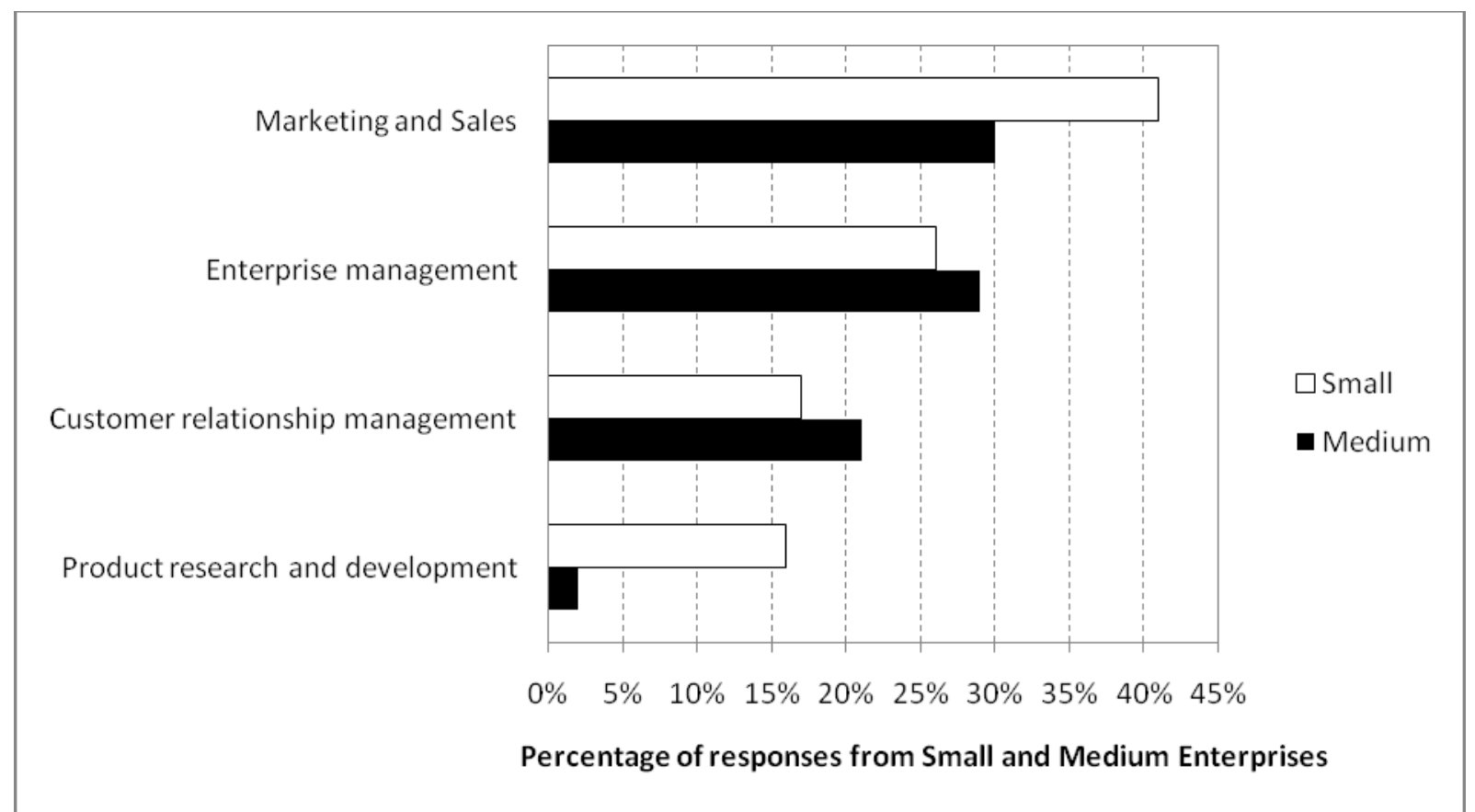

Source: Yi (2010).

Figure 1: Critical Information System (IS) areas in SMEs

In the survey conducted by this study, the Chinese SMEs indicated that for surviving in the competitive marketplace, highest priority needed to be given to IT applications in marketing and sales activities. Electronic information has been acknowledged as easier to manage than manual systems of record keeping and retrieval, and can play a strategic role in SMEs. This survey noted the heavy focus given to marketing and sales for IS by SMEs, ahead of product development and innovation, and research and development activities, which may potentially ensure longer-term sustainability for these firms. This emphasis on marketing and sales in Chinese SMEs suggests that they have a short-term perspective on IT applications for their organisational systems, which is reflective of the general approach undertaken by SMEs in running their businesses. For example, it is not unusual for SMEs to embrace a vision of their future business operations that does not extend beyond the following year, because they tend to have a life span of two to three years.

In terms of IT investment, it was found that Chinese SMEs' investment in IT training, consultancy, and maintenance, as a percentage of sales revenue, was on average $60 \%$ less than large corporations'. In addition, SMEs' investment in software, hardware, and website development, as a percentage of sales revenue, was less than $4 \%$ of their large counterparts. SMEs largely invest in basic IT applications using off-the-shelf software and often standalone applications for handling information on a non-sharing basis, for purely operational purposes. The survey found that at least half of the SMEs use manual book entry systems for their businesses. A separate survey of SMEs in Beijing found that although these enterprises have comparatively easier access to IT talents and support than SMEs in provincial locations, 50\% of their IT applications were considered obsolete (Y. Dong \& An, 2009). 


\section{Reasons for Low IT Adoption in SMEs}

\section{a) Financial Constraints}

Financial constraints have long been a major problem faced by most Chinese SMEs, among other challenges such as an unskilled labour force, poor management skills and weak innovative ability (C. Dong, 2007; Ren 2003; UNDP, 2005; Wang, 2008). These challenges have impeded SMEs' ability to invest in IT and exploit technological potential to a level where sustainability is being achieved and a positive impact on financial performance being generated.

The survey found that financial constraints constitute a pressing issue among Chinese SMEs and a major reason behind the low adoption of IT in these enterprises. The difficulty in obtaining financing has been one of the main reasons why SMEs have foundered (Wang, 2004). In the late 2000 s, $50 \%$ of non-state-owned SMEs have collapsed as a result of losses and bankruptcy (Chen, 2009). Chinese SMEs generally find it difficult to secure loans from the banks, which still regard state-owned enterprises and public-owned enterprises as their preferred borrowers. Chinese SMEs are considerably smaller than large Chinese corporations and they have generally lacked acceptable collateral. Figure 2 shows the contrasting levels of total assets, sales revenues, and total profits of large corporations and SMEs, which might explain why banks have associated SMEs with higher credit risk. The low credit rating of SMEs has made it difficult for them to be listed in the stock exchange to secure funds from investors. In addition, the Chinese capital market is still at a fledgling stage of development and unable to fully cater to the financing needs of SMEs. Despite government measures and policies designed to help SMEs, these enterprises still face difficulties in obtaining loans, and the loans they do receive are limited (Wang, 2004). As a result, they depend mainly on self-accumulated capital (such as savings or investment gains) for business investment and operations.

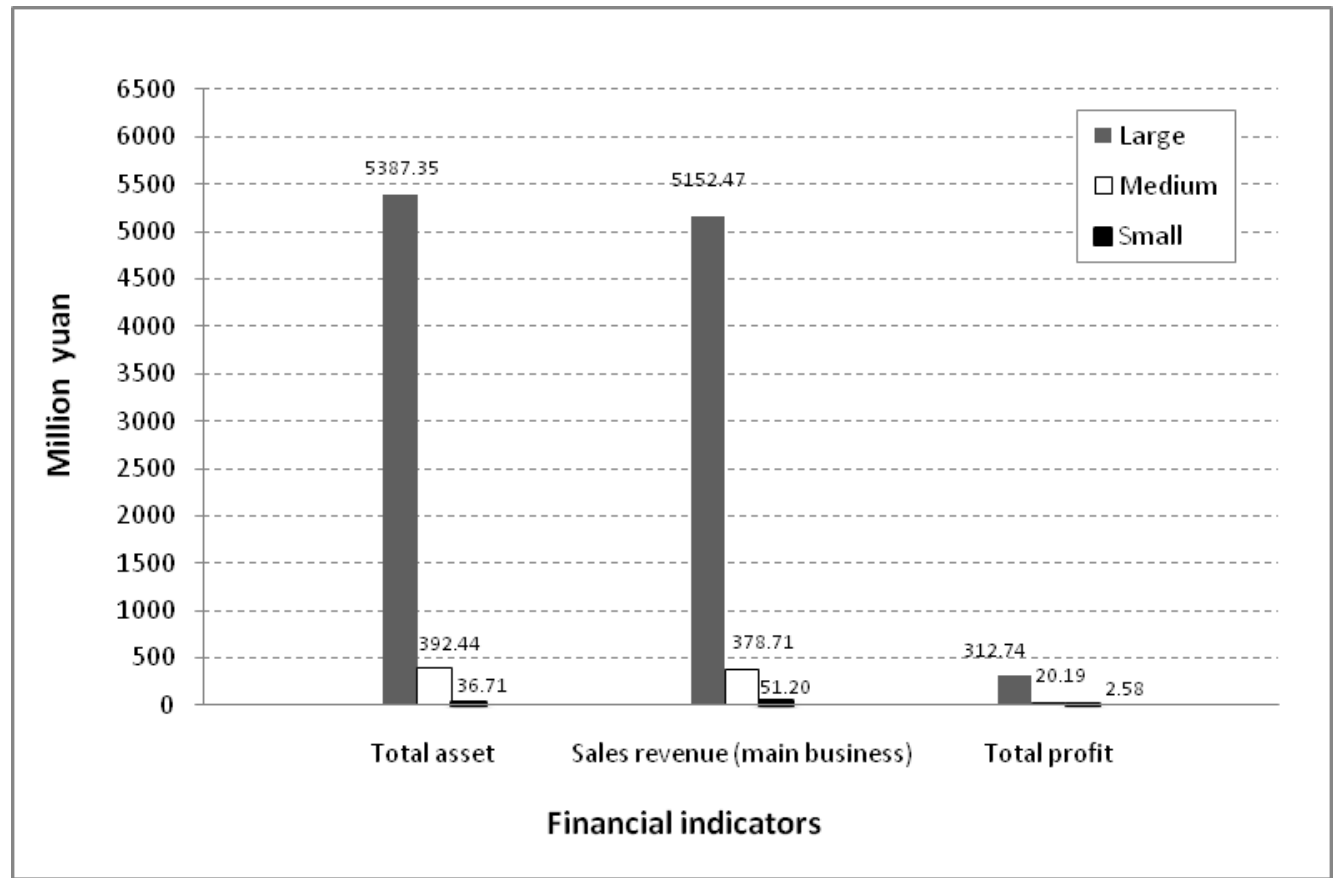

Source: Yearbook of China SMEs (2008).

Figure 2: Average total assets, sales revenues, and total profits of different-sized Chinese enterprises. 
Figure 3 shows a comparison of financing sources used by SMEs in China and the US in 2001. It reveals that Chinese SMEs' dependence on self-accumulated capital (such as savings or investment gains) is twice that of American SMEs. Their ability to borrow from their local banks is half that of their US counterparts. In addition, capital market financing for the Chinese SMEs is less than $1 \%$ of total funds. Their heavy reliance on self-accumulated capital still prevails today (Ayyagari, Kunt, \& Maksimovic, 2010; Chen, 2007).

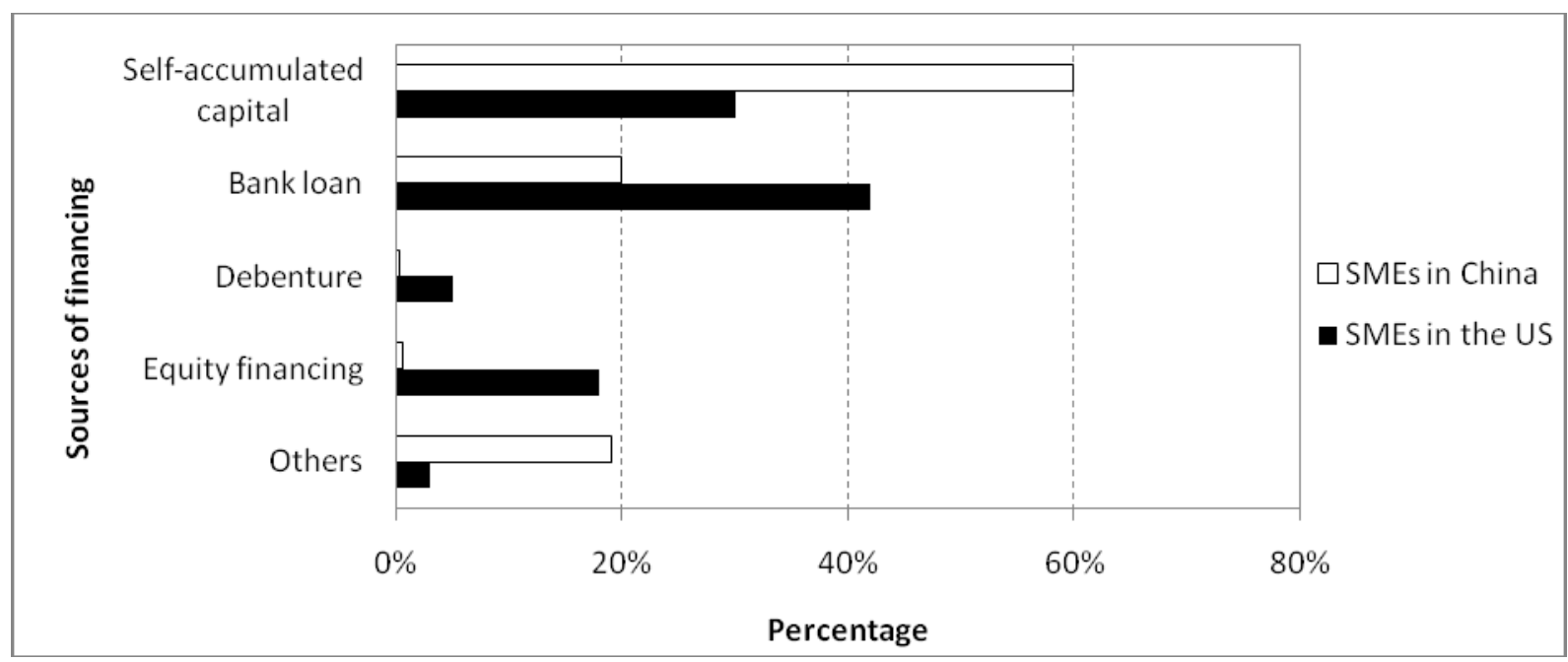

Source: Xu (2009).

Figure 3: A comparison of sources of financing between SMEs in the US and China in 2001

SMEs tend to have difficulties in meeting both the initial costs and the ongoing expenses of maintaining their operations. In particular, they find it difficult to justify a substantial financial commitment to an IT investment whose returns may not be explicit and which competes against daily operational issues that commonly take priority. IT management is not considered a major role in most SMEs. In Beijing, about $70 \%$ of SMEs do not provide a specific budget for IT or IS investment and maintenance (Y. Dong \& An, 2009).

\section{b) Lack of IT Talents}

Skilled IT staff are vital to maximising the potential, and minimising the risk, of IT adoption, through their expertise in formulating and integrating business and IT strategies. Small enterprises found it costly to hire dedicated IT staff for a business of less than 100 personnel. At the same time, they also found it difficult to hire an "all-rounded" skilled staff member who is capable of handling hardware and software aspects of IT systems, and has a hybrid knowledge of IS needs and business management strategies for implementing strategic use of IS. Furthermore, SMEs have perpetually been plagued with the problem of retaining skilled professionals due to their inability to match the salaries of large corporations. It was found that some of the staff appointed to be in charge of IT systems in SMEs lack formal training. In another survey ('Survey on current', 2010), it was found that the position of Chief Information Officer (CIO) existed in only $1.2 \%$ of 365 SMEs. This uncommon position was attributed by the researchers to a limited understanding of, and focus on, the importance of IT adoption among most SMEs. In 55\% of SMEs, the role of IS development and implementation was undertaken by the Chief Executive Officer (CEO). Although $20 \%$ of SMEs employed an information director, this position does not handle the full role and responsibilities of a CIO. In regard to the types of strategic issues on which CIOs were consulted, $90.8 \%$ of them were consulted on IT issues, and less than $50 \%$ on business/competition strategies or logistics issues. This indicates that many CIOs do not partici- 
pate in business strategic issues. This is not beneficial to the SMEs because a prerequisite for the strategic use of IT for any business is that it must have the ability to identify where IT can enhance business value, and this expertise generally rests with qualified IT professionals. This research found that in those SMEs that did not have access to a skilled IT professional, the ownermanagers tended to possess a low level of awareness of the potential of IT to enhance business operations. The absence, or low involvement, of IT on the strategic planning and business integration agenda in SMEs can lead to sub-optimal implementation and use of this technology.

The survey also found that $37.5 \%$ of CIOs possessed decision-making power, but $55 \%$ of CIOs were confined merely to offering suggestions for decision making. It was found that $6.2 \%$ of CIOs considered themselves without any form of power or authority. Interestingly, $75 \%$ of the respondents interviewed were of the view that CIO is an important position but that their position lacked power and authority. Another critical IT issue in these SMEs has been the fledgling stage of their IS and IT adoption, which is yet to generate significant benefits. There is also a low level of awareness of the rationale for, and understanding of, IT investment because organisational survival in financial terms held top priority over other issues. As a result, CEOs in these enterprises tended not to place significant importance on IT adoption or on the CIO position.

\section{Conclusion}

Some of the Chinese SMEs' problems may be alleviated or resolved by IT adoption and IS implementation such as by expanding their businesses beyond traditional marketplaces through the Internet and employing IT for improving business processes. However, these SMEs tend to hold a short-term view of their own sustainability. The lack of long-term planning and IT budgeting in these SMEs has resulted in a high level of resistance towards investing in IT that may not generate explicit financial gains or immediate realisable returns. The lack of technical resources and expertise in Chinese SMEs has also limited the awareness of owner-managers of IT potential and of the benefits of implementing strategic and integrated systems enabled by IT. This can result in an inability to use IT as strategic leverage, and in low harnessing of IT potential from existing applications in these enterprises.

Chinese SMEs require relevant IT skills and initiatives to sustain their competitiveness in both domestic and global markets. With a set of problems facing them, ranging from financing difficulties to a lack of skilled professionals, the adoption of IT can be a daunting task for such firms. Government support in the areas of financial support, ongoing consultancy, education, and training is necessary to support these SMEs through the introduction, implementation and integration of IT, as well as bringing IT to a higher level of sophistication which will have a positive impact on their long-term sustainability.

\section{References}

Ayyagari, M., Kunt, A. D, \& Maksimovic, V. (2010). Formal versus informal finance: Evidence from China. The Review of Financial Studies, 23(8), 3049-3097.

Azumah, G., Koh, S. C. L., \& Maguire, S. (2005). E-organisation and its future implication for SMEs. Production Planning \& Control, 16(6), 555-562.

Barua, A., Konana, P., Whinston, A. B., \& Yin F. (2004). An empirical investigation of net-enabled business value. MIS Quarterly, 28(4), 585-620.

Bala, H., \& Venkatesh, V. (2007). Assimilation of interorganizational business process standards. Information Systems Research, 18(3), 340-362.

Brynjolfsson, E., \& Hitt, L. (1995). Information technology as a factor of production: The roles of differences among firms. The Economics of Innovation and Technology, 3, 183-199. 
Brynjolfsson, E., \& Hitt, L. (1996). Paradox lost? Firm-level evidence on the returns to information system spending, Management Science, 42(4), 541-558.

Camarinha-Matos, L. M., \& Afsarmanesh, H. (2005). Collaborative networks: A new scientific discipline. Journal of Intelligent Manufacturing, 16, 439-52.

Chen, R. X. (2009). China's SMEs Development Report (2008-2009). Beijing: China Economic Publishing House.

Chen, X. L. (2007). SME financing in China. EconPapers No. 2007-29. Retrieved November 16, 2010 from http://economix.u-paris10.fr/pdf/dt/2007/WP_EcoX_2007-29.pdf

Davidow, W., \& Malone, M. (1992). The Virtual Corporation. New York: Harper Business.

Dong, C. (2007). Discussion on the position and role of small and medium enterprises and corresponding policies and regulations. Sichman Accounting, 5, 10-11.

Dong, Y., \& An, M. S. (2009). Analysis of SMEs' IT governance problem. In Yang Yi, Tao Qui Yen and Dong Yan (Eds.). Analysis of SMEs' compeling problems in growth and development (pp.201-209). Beijing: China Economic Publishing House.

Freland, J. E., \& Morris, C. E. (1976). A cross section analysis of small business failure. American Journal of Small Business, 1(1), 7-18.

Gosain, S., Malhotra, A., \& El Sawy, O. A. (2004) Coordinating for flexibility in e-business supply chains. Journal of Management Information Systems, 21(3), 7-45.

Gulati, R. (1998). Alliances and networks. Strategic Management Journal, 19(4), 293-317.

Hitt, L., \& Brynjolfsson, E. (1996). Productivity, business profitability, and consumer surplus: Three different measures of information technology value. MIS Quarterly, 20(2), 121-142.

International Telecommunication Union (ITU). (2009). The world in 2009: ICT facts and figures. Retrieved October 27, 2010 from http://www.itu.int/ITU-D/ict/material/Telecom09 flyer.pdf

Jeffcoate, J., Chappell, C., \& Feindt, S. (2002). Best practice in SME adoption of e-commerce. Benchmarking: An International Journal, 9(2), 122-132.

Jennings, P. L., \& Beaver, G. (1997). The performance and competitive advantage of small firms: A management perspective. International Small Business Journal, 15(2), 63-75.

Johnson, G., \& Scholes, K. (1993). Exploring corporate strategy. London: Prentice-Hall.

King, W. R., Grover, V., \& Hufnagel, E. H. (1989). Using information and information technology for sustainable competitive advantage: Some empirical evidence. Information and Management, 17(2), 87-93.

Koh, S. C. L., \& Maguire, S. (2004). Identifying the adoption of e-business and knowledge management within SMEs. Journal of Small Business and Enterprise Development, 11(3), 338-348.

Koh, S. C. L., \& Simpson, M. (2005). Change and uncertainty in SME manufacturing environments using ERP. Journal of Manufacturing Technology Management, 16(6), 629-653.

Lee, B., \& Barua, A. (1999). An integrated assessment of productivity and efficiency impacts of information technology investments: Old data, new analysis and evidence. Journal of Productivity Analysis, 12, 21-43.

Lee, S. C., Pak, B. Y., \& Lee, H. G. (2003). Business value of B2B electronic commerce: the critical role of inter-firm collaboration. Electronic Commerce Research and Applications, 2(4), 350-361.

Lichtenberg, F. (1995). The output contributions of computer equipment and personnel: A firm level analysis. The Economics of Innovation and Technology, 3, 201-217.

Malecki, E., \& Tootle, D. (1996). The role of networks in small-firm competitiveness. International Journal Technology Management, 11(1/2), 43-57. 
Monteiro, L., \& Macdonald, S. (1996). From efficiency to flexibility: The strategic use of information in the airline industry. Journal of Strategic Information Systems, 5(3), 169-188.

Mowshowitz, A. (1997). Virtual organization. Communications of the ACM, 40(9), 30-37.

Patterson, R. A., Kozmetsky, G., \& Ridgway, N. M. (1983). Perceived causes of small business failures: A research note. American Journal of Small Business, 8(1), 15-19.

Poon, S., \& Swatman, P. (1997). Small business use of the Internet: Findings from Australian case studies. International Marketing Review, 15(5), 385-402.

Porter, M. E., \& Miller, V. E. (1985). How information gives you competitive advantage. Harvard Business Review, July-August, 149-160.

Prater, E., \& Ghosh, S. (2006). A comparative model of firm size and the global operational dynamics of U.S. firms in Europe. Journal of Operations Management, 24(5), 511-529.

Rackoff, N., Wiseman, C., \& Ulrich, W. A. (1985). Information systems for competitive advantage: Implementations of a planning process. MIS Quarterly, 9(4), 285-295.

Ren, J. (2003). The application of analysis hierarchy process on the SMEs' competitiveness evaluation. Systems Engineering - Theory \& Practice, 3, 91-95.

Silvius, A. J. G. (2006). Does ROI matter? Insights into the true business value of IT. The Electronic Journal Information Systems Evaluation, 9(2), 93-104.

Snow, C. C., Miles, R. E., \& Coleman, J. R. (1992). Managing $21^{\text {st }}$ century network organizations. Organizational Dynamics, 20(3), 5-20.

Stockdale, R., \& Standing, C. (2004). Benefits and barriers of electronic marketplace participation: An SME perspective. The Journal of Enterprise Information Management, 17(4), 301-311.

Suarez-Villa, L. (1998). The structures of cooperation: Downscaling, outsourcing, and the networked alliances. Small Business Economics, 10(1), 5-16.

Survey on current sustainability of CIO in SMEs. (2010). Retrieved November 16, 2010 from http://biyenlunwen.yjbys.com

United Nations Development Programme. (2005). Country evaluation: Assessment of development results, China. Retrieved November 16, 2010 from http://www.undp.org/eo/documents/ADR/ADR_Reports/ADR_China.pdf

Walton, L. W., \& Miller, L. G. (1995). Moving toward LIS theory development: A framework of technology adoption within channels. Journal of Business Logistics, 16(2), 117-136.

Wang, L. (2008). SME development policies in China: A country paper for the workshop on SME development and regional economic integration. China: Ministry of Industry and Information Technology. Retrieved July 1, 2009 from http://www.adbi.org/files/2008.09.23.cpp.paper.china.sme.dev.mngt.pdf

Wang, Y. (2004). Financing difficulties and structural characteristics of SMEs in China. China \& World Economy, 12(2), 34-49.

Watson, J. (2003). The potential impact of accessing advice on SME failure rates. A paper for the Small Enterprise Association of Australia and New Zealand $16^{\text {th }}$ Annual Conference, Ballarat, 28 Sept -1 Oct, 2003. Retrieved 16, 2010, from http://www.cric.com.au/seaanz/resources/10WatsonThepotentialimpactofaccessingadvicefinal.pdf

Wei, H., \& Wang, E. T. G. (2010). The strategic value of supply chain visibility: Increasing the ability to reconfigure. European Journal of Information Systems, 19(2), 238-249.

Wichmann, H. (1983). Accounting and marketing - Key small business problems. American Journal of Small Business, 7(4), 19-26.

Xu, J. (2009). Breakthrough in SMEs' developmental growth: Financing bottleneck and credit. Beijing: People Press. 
Yearbook of China SMEs. (2008). Yearbook of China Small and Medium Enterprises 2008. Beijing: Economic Science Press.

Yi, M. (2010) Information survey reflects tight situation in SMEs. Retrieved 17, 2010 from http://soft.chinabyte.com

\section{Biography}

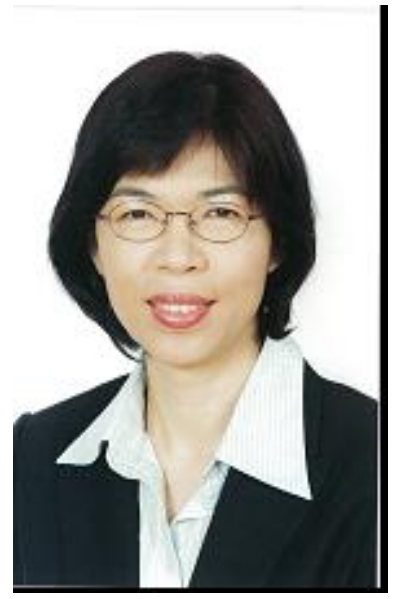

Dr. Michelle W. L. Fong is a senior lecturer in the School of Accounting and Finance, Victoria University. She has taught in Australia, China, Malaysia, and Singapore. Prior to her academic and research career, she worked with a range of organizational systems in corporations based in different countries. Her research interest includes information technology applications, e-business, and online education. 